\title{
The Use of SEM in Studying Infected Chicken Eggs by Salmonella
}

\section{typhimurium}

\author{
Ibtisam M. Al-Lawati, Saif N. Al-Bahry, Taher A. Ba-Omar and AbdulQader \\ Elshafie
}

Department of Biology, College of Science, Sultan Qaboos University, P.O.Box 36 Al-Khod 123, Muscat, Sultanate of Oman.

The major out breaks caused by Salmonella (spp) was traced back from infected eggs (Gast and Beard 1992). Few studies were carried out on the penetration of Salmonella (spp) into the eggs. Egg membrane acts as an important physical barrier that hinders penetration of bacteria into nutrient rich inner egg compartments, albumin and yolk. Infection and penetration of Salmonella typhimurium (ST), (ATCC 14042) into domestic chicken eggs (Bovan brown (BB)) and subsequent phases to establish infection were investigated in this study.

Chicken eggs were exposed to ST cultures of $1 \times 10^{6}$ cells $/ \mathrm{ml}$ for $5,15,30$ and 45 min. at $37^{\circ} \mathrm{C}$ and $\mathrm{pH}(7)$. Small pieces of outer and inner membrane $\left(1 \mathrm{~cm}^{2}\right)$ were placed on top of a carbon background on aluminum stubs and allowed to air dry in a petri dish, followed by gold coating using sputter coater (BIO-RAD, SEM coating system, UK) for 10 min. All samples were placed in the SEM (JEOL 5600 LV-low vacuum).

The infection process was followed into the outer membrane (Fig. 1) and inner membrane (Fig. 2) of eggs using scanning electron microscope (SEM). The degree of infection was found be affected by time. The intensity of ST cells in two egg compartments increased significantly $\left(37^{\circ} \mathrm{C}, \mathrm{pH} 7\right)$ as time of incubation as indicated above (Fig. 1a-1e, and Fig. 2a-2e).

\section{References}

Gast, R. and C. Beard 1992. Detection and enumeration of SE in fresh and stored eggs

laid by experimentally infected hens. J. Food. Prot. \%\%:152-156. 


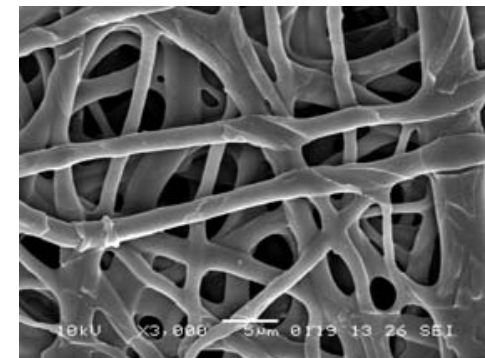

a

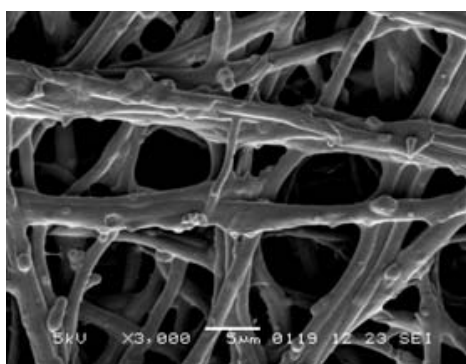

b

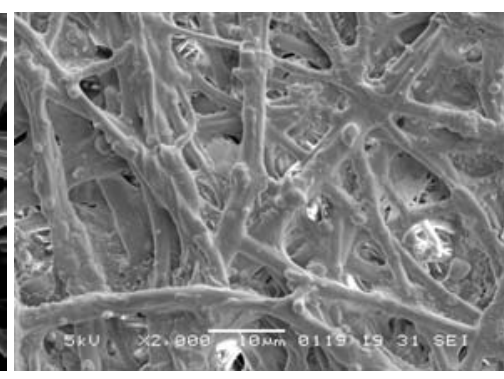

c

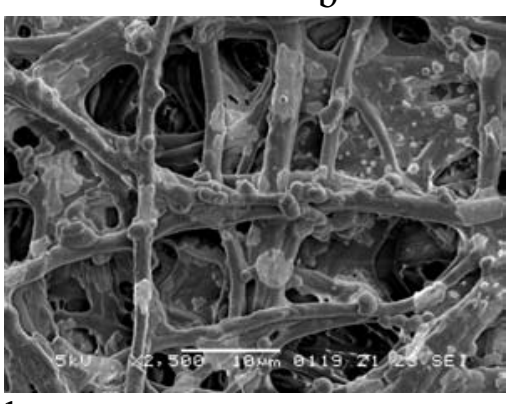

d

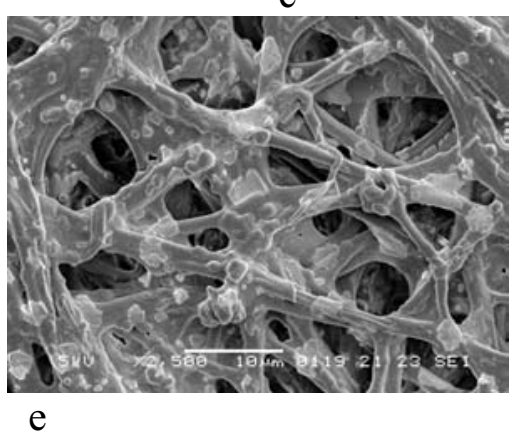

Fig.1. Penetration of ST into outer membrane of chicken egg, $a=$ control, $b=5 \mathrm{~min}$, $\mathrm{c}=15 \mathrm{~min}, \mathrm{~d}=30 \mathrm{~min}$, and $\mathrm{e}=45 \mathrm{~min}$.

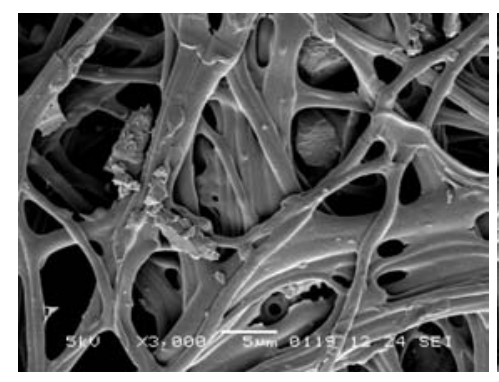

a

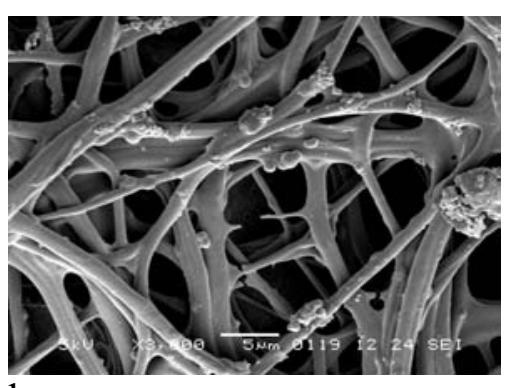

b

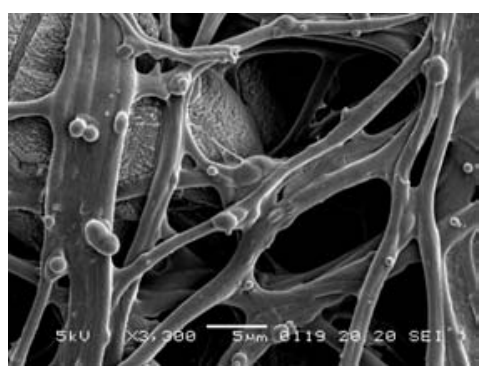

c

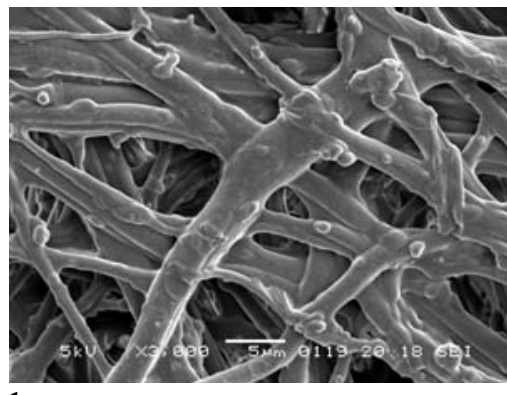

d



e

Fig 2. Penetration of ST into inner membrane of chicken egg, $a=$ control, $b=5 \mathrm{~min}$, $\mathrm{c}=15 \mathrm{~min}, \mathrm{~d}=30 \mathrm{~min}$, and $\mathrm{e}=45 \mathrm{~min}$. 